\title{
Alterations in Postnatal Intestinal Function during Chronic Hypoxemia ${ }^{1}$
}

\author{
DANIEL BERNSTEIN, JANET G. BELL, LINDA KWONG, AND RICARDO O. CASTILLO \\ Divisions of Cardiology [D.B.] and Gastroenterology [J.G.B., L.K., R.O.C.], Department of Pediatrics, \\ Stanford University, Stanford, California 94305
}

\begin{abstract}
Growth failure is a major complication of chronic hypoxemia, as seen in infants and children with cyanotic congenital heart disease. To determine whether chronic hypoxemia during infancy affects the gastrointestinal tract, we examined small intestinal growth and digestive enzyme activities in chronically hypoxemic newborn lambs and in age-matched controls. Chronic hypoxemia was produced by placing an inflatable occluder around the main pulmonary artery and performing a balloon atrial septostomy. Aortic oxygen saturation was reduced to 60$74 \%$ for $2 \mathrm{wk}$, after which the small intestine was removed for analysis. During chronic hypoxemia, somatic growth rate was decreased to $60 \%$ of control (hypoxemic, $135 \pm$ 20 versus control, $216 \pm 26 \mathrm{~g} / \mathrm{d}, p<0.02)$. No differences in caloric intake were found (hypoxemic, $129 \pm 4$ versus control, $128 \pm 4 \mathrm{kcal} / \mathrm{kg} / \mathrm{d}$ ). Chronic hypoxemia did not alter small intestinal growth, as measured by jejuno-ileal weight, jejuno-ileal length, mucosal weight, or mucosal protein or DNA contents. However, sp act of lactase, the principal disaccharidase of the infant lamb intestine, were significantly decreased (hypoxemic, $0.08 \pm 0.01$ versus control, $0.146 \pm 0.03$ units of enzyme activity/mg DNA, $p$ $<0.05$ ), as were the total small intestinal contents of lactase (hypoxemic, $61.7 \pm 7.0$ versus control, $120.6 \pm$ 21.7 units of enzyme activity, $p<0.01$ ). There also were decreases in specific and total activities of other digestive enzymes such as maltase, amino-oligopeptidase, and alkaline phosphatase in hypoxemic intestine that did not achieve statistical significance. In conclusion, chronic hypoxemia in infancy is associated with decreases in activities of intestinal lactase, which may result in diminished capacity for absorption of dietary carbohydrate. Alterations in intestinal function may contribute to growth failure associated with chronic hypoxemia. (Pediatr Res 31: 234-238, 1992)
\end{abstract}

\section{Abbreviations}

AOP, amino-oligopeptidase

UE, unit of enzyme activity

$\mathrm{VO}_{2}$, oxygen consumption

Received June 22, 1990; accepted November 8, 1991

Correspondence and reprint requests: Daniel Bernstein, M.D., Department of Pediatrics, Stanford University, Stanford, CA 94305.

Supported in part by a FIRST award to D.B. from the National Institutes of Health (HL38741) and by a Grant-in-Aid from the American Heart Association, California Affiliate. R.O.C. is the recipient of Clinical Investigator Award (HD00779) from the National Institutes of Health.

${ }^{1}$ Presented in part at the Annual Meeting of the Society for Pediatric Research, Washington, DC, May 1989, and published in abstract form (Pediatr Res 25:21A, 1989).
Growth failure is a major complication of chronic hypoxemia, as seen in infants and children with cyanotic congenital heart disease $(1,2)$. Although there have been several previous investigations to determine the etiology of this growth failure (3-7), the exact mechanisms are still not well defined. Several studies suggest that gastrointestinal tract function may be impaired during hypoxemia $(3,8-12)$; however, many of these experiments have been performed during acute rather than chronic hypoxemia $(8,9,11,12)$ and on adult rather than on immature subjects $(8,11,12)$. Previous studies performed on hypoxemic human neonates were inadequately controlled for factors other than hypoxemia, such as prematurity, pulmonary disease, and heart failure $(5,13)$. Finally, data from previous studies using models of alveolar hypoxemia may not be applicable to patients with cyanotic heart disease, in whom hypoxemia is associated with intracardiac right to left shunting. In these patients, hemodynamic alterations secondary to structural heart defects may also contribute to the failure to grow.

To better elucidate the hemodynamic mechanisms underlying growth failure during chronic hypoxemia, Teitel et al. (6) developed a model of cyanotic congenital heart disease in the newborn lamb. These authors determined that chronically hypoxemic lambs grew at one fourth the rate of their age-matched controls. Using this model, we have previously reported a decrease in gastrointestinal tract blood flow and oxygen delivery during chronic hypoxemia, and have postulated that these changes could alter intestinal function (14). Thus, the purpose of the current study was to determine whether chronic hypoxemia, secondary to an intracardiac right to left shunt during the newborn period, results in alterations in growth or enzymology of the small intestine. Because it has also been suggested that reduced caloric intake may contribute to the growth failure associated with cyanotic congenital heart disease $(3,10)$, we also sought to determine whether chronic hypoxemia was associated with a decrease in dietary intake and, thus, in nutrient delivery to the gastrointestinal tract.

\section{METHODS}

Surgical preparation. Chronic hypoxemia was produced in 12 newborn lambs using a model of cyanotic congenital heart disease developed by Teitel et al. (6). Briefly, surgery was performed on newborn lambs of mixed Western breed during the 1st week of life. Polyvinyl catheters were inserted via a hind leg pedal artery and vein and advanced into the descending aorta and inferior vena cava. Under general anesthesia, a thoracotomy was performed in the 4th left intercostal space. Polyvinyl catheters were inserted into the ascending aorta, superior vena cava, right ventricle, pulmonary artery, and left atrium. A 5 F Fogarty dilation catheter (American Edwards Laboratories, Irvine, CA) was inserted via the hind leg pedal vein and advanced by direct visualization into the left atrium. A balloon atrial septostomy was then performed. The atrial septal defect was sized by passing the partially inflated balloon catheter across the defect, and additional septostomies were performed if necessary. Next, an 
inflatable silicone rubber balloon occluder with polyvinyl tubing was placed around the main pulmonary artery. This balloon occluder was left deflated during the immediate postoperative period and in this state was nonrestrictive. All catheters were filled with heparin, plugged, and brought to the skin via an s.c. tunnel and were protected by a zippered vest worn by the lamb. The lambs were then returned to their cages and were bottle-fed throughout the study period. The intravascular catheters were flushed with saline and reheparinized daily during the 2-wk study period. Antibiotics (Dual-Pen; Tech America, Kansas City, MO) were given intramuscularly immediately before each catheter flushing. Intramuscular iron dextran complex (equivalent to 100 mg of elemental iron) was given weekly to avoid the hemodynamic effects of iron deficiency.

After the lambs recovered for $3 \mathrm{~d}$, hypoxemia was produced by gradually inflating the pulmonary arterial occluder balloon with saline, which partially obstructed the right ventricular outflow tract and induced atrial right to left shunting. The details of this gradual inflation procedure have been published previously (6). Aortic oxygen saturation was measured by hemoximeter (OSM3; Radiometer, Copenhagen, Denmark). By adjusting the degree of balloon inflation, aortic oxygen saturation was decreased to 60 to $74 \%$ and was maintained at this level for $2 \mathrm{wk}$. Ten additional lambs also underwent thoracotomies and placement of intravascular catheters but did not have atrial septostomies or balloon occluders placed and served as normoxemic controls.

The lambs were bottle-fed Land O'Lakes (Arden Hills, MN) lamb milk replacer, consisting of $39 \%$ carbohydrates (primarily lactose), $24 \%$ protein, and $30 \%$ fat. This formula supplies 0.9 $\mathrm{kcal} / \mathrm{mL}$. The volume and frequency of feedings were a maximum of $475 \mathrm{~mL}$ daily in six separate feedings from the 1 st to the $3 \mathrm{rd}$ days of life, a maximum of $710 \mathrm{~mL}$ daily in three feedings up to $2 \mathrm{wk}$, and then ad libitum quantities in three daily feedings afterwards. Daily oral intake and weekly weight gain were recorded. Growth rate was calculated as weight gain $(\mathrm{g} / \mathrm{d})$.

Analysis of intestinal tissues. Investigations of intestinal tissues were performed on 12 lambs after 2 wk of hypoxemia [age $27 \pm$ 4 (SD) d] and on 10 age-matched controls (age $24 \pm 2 \mathrm{~d}$, NS). All lambs were killed at least $2 \mathrm{~h}$ after their last feeding to minimize artifacts secondary to recent oral intake (15). After the lambs were killed with i.v. pentobarbital $(90 \mathrm{mg} / \mathrm{kg})$, the small bowel was rapidly removed from the pyloric sphincter to the cecum and the total length was measured after extension of the intestine to its full length by gentle traction. The intestine was rapidly divided into four equal segments, flushed with cold isotonic saline, dried, weighed, and placed over ice. Fifteen percent of total length of the proximal segment was taken from the midpoint and used for biochemical analysis. The segment was incised longitudinally over ice, and the mucosa was removed using a glass slide, weighed, and homogenized in nine volumes of $10 \mathrm{mM}$ sodium phosphate, $5 \mathrm{mM}$ Tris- $\mathrm{HCl}, 0.002 \%$ Triton $\mathrm{X}-100, \mathrm{pH}$ 6.0. DNA and protein were quantitated by fluorometric assay (16) and by the method of Lowry (17), respectively. Lactase and maltase were measured by the glucose oxidase colorimetric assay of Dahlquist, as modified by Tsuboi (18). Cellobiose $(15 \mathrm{mM})$ was used as substrate for measurement of brush border activities of lactase. Activity of AOP was determined by the method of Wojnarowska and Gray (19). Alkaline phosphatase activity was determined by the $p$-nitrophenylphosphate method (20). $\mathrm{Na}^{+}-\mathrm{K}^{+}$-ATPase activity was determined by the method of Yoshida as modified by Matsukawa (21). UE were expressed as $\mu \mathrm{mol}$ of substrate hydrolyzed per min. Specific activities were expressed as enzyme activity per mg of DNA. Total intestinal enzyme activities were calculated by multiplying the enzyme content of the analyzed segment by 6.66 to arrive at the total enzyme content of the segment analyzed, then multiplying by 4 .

Statistical comparisons were made with an unpaired $t$ test, and data are shown as the mean \pm SEM. Because we were comparing only one experimental group with one control group under only one set of experimental conditions, we considered the individual $t$ tests to be members of separate families, and, thus, we did not perform a Bonferroni correction for multiple comparisons (22, 23). Statistical significance was considered achieved when $p<$ 0.05 .

\section{RESULTS}

Somatic growth and dietary intake. Lambs in the experimental group grew normally until the onset of hypoxemia, after which they grew at approximately one third the rate of the controls (Fig. $1 A$ ). Caloric intake per $\mathrm{kg}$ of body weight per $\mathrm{d}$ in hypoxemic lambs was not different from that in the controls at any time (Fig. $1 B$ ). Caloric intake averaged $129 \pm 4 \mathrm{kcal} / \mathrm{kg} / \mathrm{d}$ in hypoxemic lambs versus $128 \pm 4 \mathrm{kcal} / \mathrm{kg} / \mathrm{d}$ in controls (NS). No significant changes were noted in total $\mathrm{mL}$ consumed per animal per d until $21 \mathrm{~d}$ of age, at which point growth had already slowed significantly. Therefore, chronic hypoxemia did not result in reduction of nutrient intake indexed to body size, indicating that alterations in somatic growth were not due to alterations in caloric consumption.

Intestinal growth and enzymology. There were no differences between the hypoxemic and control groups in small intestinal weight or length (Table 1). Total mucosal weight, protein content, and DNA content were also similar in the two groups (Table 1). These data indicate that chronic hypoxemia, as produced by our model, did not result in impaired growth of the small intestine.

The sp act of lactase were diminished by $43 \%$ in hypoxemic intestine $(p<0.05)$ (Fig. 2). This difference persisted when lactase activity was expressed per mg protein (hypoxemic, $4.60 \pm 0.42$ versus control, $8.43 \pm 1.85 \mathrm{UE} / \mathrm{mg}$ protein, $p<0.05)$. Specific activities of maltase and AOP were reduced, but failed to reach statistical significance. Although alkaline phosphatase $(p=0.15)$ and $\mathrm{Na}^{+}-\mathrm{K}^{+}$-ATPase $(p=0.29)$ were decreased in the hypoxemic lambs, the differences failed to reach statistical significance be-
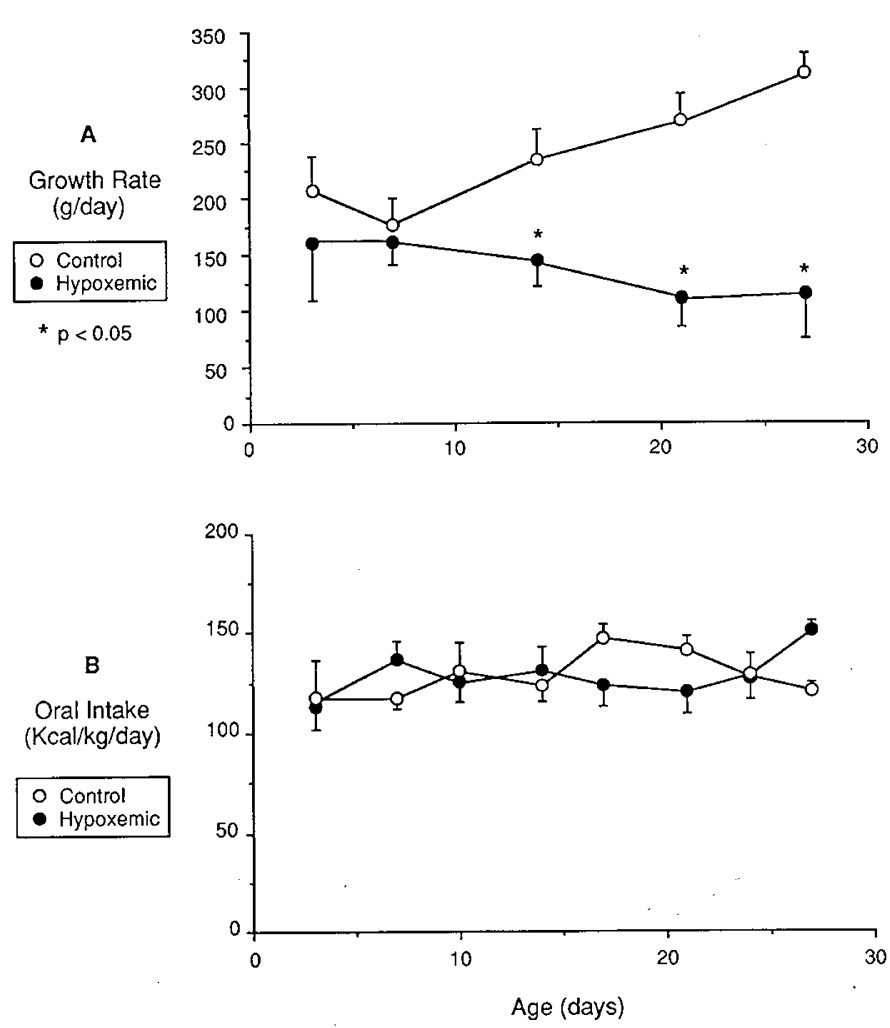

Fig. 1. Growth rate $(A)$ and oral intake $(B)$ indexed to total body weight compared between chronically hypoxemic lambs and controls. *, $p<0.05$ by $t$ test. 
Table 1. Comparison of selected intestinal parameters between hypoxemic and control lambs*

\begin{tabular}{lcc}
\hline & Hypoxemic & Control \\
\hline Total intestinal parameters & & \\
$\quad$ Small intestinal wt $(\mathrm{g})$ & $164 \pm 9$ & $186 \pm 15$ \\
$\quad$ Small intestinal length $(\mathrm{m})$ & $13.7 \pm 0.4$ & $13.3 \pm 1.0$ \\
Mucosal parameters & & \\
$\quad$ Total mucosal wt $(\mathrm{g})$ & $121 \pm 8$ & $139 \pm 13$ \\
$\quad$ Mucosal protein content $(\mathrm{g})$ & $14.6 \pm 1.1$ & $16.6 \pm 1.6$ \\
Mucosal DNA content $(\mathrm{g})$ & $0.89 \pm 0.08$ & $0.94 \pm 0.08$ \\
\hline
\end{tabular}

* All were nonsignificant by $t$ test.
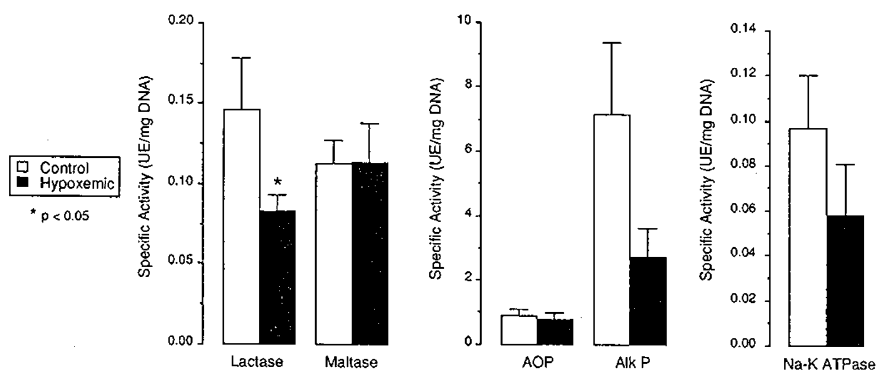

Fig. 2. Comparison of enzyme sp act, given as UE/mg DNA, between chronically hypoxemic and control lambs. ${ }^{*}, p<0.05$ by $t$ test.
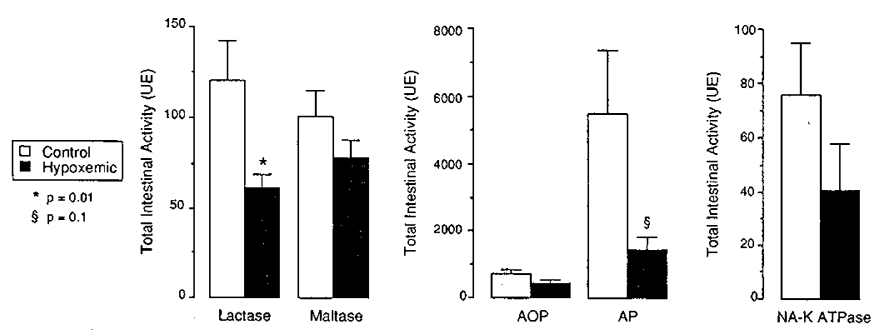

Fig. 3. Comparison of total intestinal enzyme activities, given as UE/ intestine, between chronically hypoxemic and control lambs. ${ }^{*}, p<0.01$; $\S, p=0.1$ by $t$ test.

cause of large intragroup variance. Total intestinal activity of lactase was $49 \%$ lower in hypoxemic lamb intestine $(p=0.01)$ (Fig. 3). Total intestinal activities of maltase, AOP, alkaline phosphatase, and $\mathrm{Na}^{+}-\mathrm{K}^{+}$-ATPase were also lower in hypoxemic intestine, but these differences did not reach statistical significance.

\section{DISCUSSION}

In a model of cyanotic congenital heart disease in the newborn lamb, chronic hypoxemia did not result in impaired postnatal growth of the small intestine in spite of marked reduction in somatic growth. Small intestinal length, weight, total mucosal weight, and total mucosal DNA and protein did not differ between infant lambs that were hypoxemic for $2 \mathrm{wk}$ and normoxemic controls (Table 1). This indicates that cellular proliferation in the small intestine of the infant lamb is not impaired by chronic hypoxemia. In contrast, the sp act (UE/mg DNA) of intestinal lactase, the major disaccharidase of the infant lamb intestine (1), were significantly lower in the hypoxemic animals, indicating that the cellular concentration of lactase was lower in the intestines of hypoxemic lambs (Fig. 2). The decreased total intestinal activity of lactase (Fig. 3) is therefore not due to diminished numbers of absorptive cells having normal complements of lactase, but to normal numbers of cells that have lower lactase activity per cell. It is known that lactase undergoes intracellular synthesis, processing, and transport to the brush border surface where degradation of the enzyme occurs $(24,25)$. Diminished catalytic activities of lactase in the current studies may be due to diminished synthesis of the enzyme (25), altered intracel- lular processing resulting in either intracellular degradation (26) or inactive enzyme protein (27), or slowed transport and delivery to the brush border or may be a consequence of more rapid degradation after insertion into brush border sites (24). It is tempting to speculate that the mechanism that produces the reduction in catalytic activity is a mechanism that is directly linked to hypoxemia. Alternatively, we have previously described a decrease in gastrointestinal tract blood flow and oxygen delivery during chronic hypoxemia using this same model (14). Thus, the abnormalities of lactase in the current study could be secondary to the direct effects of reduced oxygen tension, to altered gastrointestinal tract blood flow, or to altered gastrointestinal tract oxygen delivery. In this regard, we have shown that reductions in intestinal oxygen delivery without commensurate decreases in blood flow are not associated with abnormalities of growth (28). We have also shown that chronically hypoxemic lambs do not manifest signs of right heart failure, which could interfere with intestinal function (6). However, further studies will be necessary to better separate the effects of hypoxemia from those of altered hemodynamics.

Although chronic hypoxemia resulted in cessation of somatic growth in our lambs (Fig. 1A), it is unlikely that the alterations observed in the small intestine are due to malnutrition. Nutrient consumption, expressed as the caloric intake per $\mathrm{kg}$ body weight, was not different between the two animal groups (Fig. 1B). Malnutrition produces characteristic changes in the small intestine that include mucosal atrophy [diminished mucosal protein and DNA and decreased rates of cellular proliferation (29)], as well as a characteristic array of enzymic alterations. Lactase activity levels are increased in malnutrition, whereas the activities of other digestive hydrolases, such as sucrase and maltase, are decreased $(30,31)$. In contrast, the small intestine of hypoxemic lambs showed no differences in mucosal weight, protein, or DNA contents. This indicates that the amount of absorptive surface is the same in the two animal groups, inasmuch as mucosal DNA and protein are highly correlated with villus height, villus number, and mitotic index (32). In addition, both specific and total activities of intestinal lactase were decreased, not increased, in chronically hypoxemic lambs, suggesting that this change was not due to malnutrition.

Analysis of total intestinal activities of the digestive hydrolases is useful because expressing the data as total activity removes the possibility of artifact when the data are related to DNA or protein (33) and total intestinal levels of digestive enzymes are correlated with the digestive capacity for the substrate of the enzyme. The decrease in total activities of lactase demonstrated in this study suggests that chronic hypoxemia during the newborn period may result in diminished digestive capacity for lactose, the major dietary carbohydrate consumed during infancy. This may result in diminished absorption of lactose and other nutrients, either producing or contributing to the profound growth failure seen in hypoxemic infant lambs. It is of interest that the hypoxemic lambs in our study did not show any of the clinical signs of lactose intolerance, such as diarrhea. This suggests that although hypoxemic lambs had diminished total intestinal capacities for digestion of lactose the levels of lactose consumed did not exceed that capacity.

Our finding of decreased lactase activity is in contrast to the results of previous studies by Lifshitz et al. (11) and Berant et al. (8) in adult animals, which failed to show changes in brush border disaccharidase levels after short intervals of alveolar hypoxemia. This is most likely attributable to the longer duration of hypoxemia in the current study, but might also reflect differences between species, the influence of additional hemodynamic abnormalities in our model that are not present during alveolar hypoxemia, or possibly a unique susceptibility of the infant intestine to the effects of hypoxemia. Previous studies of acute hypoxemia in adult animals have also demonstrated a reduction in absorption of the actively transported sugars glucose and galactose $(8,9,12)$ and reduction in activity of the $\mathrm{Na}^{+}-\mathrm{K}^{+}-$ 
ATPase. In our studies, sp act of alkaline phosphatase were reduced by $72 \%$ and sp act of $\mathrm{Na}^{+}-\mathrm{K}^{+}$-ATPase were reduced by $40 \%$ in intestines of chronically hypoxemic lambs compared with control. Although these results did not achieve statistical significance because of large variances, it is possible that these trends indicate that the activities of these two enzymes are indeed reduced in chronically hypoxemic infant intestine. Others have demonstrated alterations in glucose, protein, and fat absorption in hypoxemic human infants, although the effects of other factors such as prematurity and heart failure were not well controlled $(5,13)$. One study was performed using breath test techniques to evaluate lactose malabsorption in a group of 20 infants with cyanotic and acyanotic heart disease (34). Although only two infants were found to have positive breath tests, the breath test methodology was not validated for use in this clinical setting by the authors. In particular, a nonabsorbable carbohydrate, such as lactulose, should have been administered as a control to show that appreciable levels of hydrogen were excreted in breath. It is theoretically possible that in the presence of cyanotic heart disease, decreased blood flow to the lungs could result in impaired pulmonary excretion of hydrogen resulting in false negative results.

Past studies have produced conflicting results regarding the role of oral intake in hypoxemic growth failure. Elliott and Cheek (10) measured oral intake in hypoxemic rats and demonstrated that pair-fed normoxic rats also failed to grow, although the severity of the hypoxic growth failure was not totally accounted for by reduced intake (3). Studies in hypoxemic human infants $(7,35)$ and in children living at high altitude $(36,37)$ have also produced conflicting results as to the exact contribution of malnutrition in the etiology of hypoxic growth failure. Although several studies have described alterations in physical growth of infants and children living at high altitude $(38,39)$, interpretation of these studies has been confounded by differences in socioeconomic status and racial background $(36,37,40)$. Finally, increased cardiorespiratory work during chronic hypoxemia may result in an increase in caloric requirements $(4,5)$. Although total body $\mathrm{VO}_{2}$ in our lambs has been shown to be unchanged from control levels $(6,7)$, an increase in cardiorespiratory $\mathrm{VO}_{2}$ may be counterbalanced by a decrease in $\mathrm{VO}_{2}$ directed toward growth $(6,41)$.

A potential limitation of the current study concerns the appropriateness of the lamb as a model for the study of digestive enzyme function in cyanotic congenital heart disease. The advantages of this model are that the hemodynamic characteristics and failure of growth have already been well characterized (6, 14,28 ). Developmental differences in digestive enzyme activity have been little studied in the lamb. Lactase and maltase activities have been characterized in the newborn lamb and have been shown to remain at stable levels during the first 3-5 wk of life (42). Generally, digestive enzymes exhibit an aboral gradient in most species, and this may be the case for lactase in the infant lamb intestine (43). Because of the likelihood that gradients were in fact present in our suckling lambs, we based our calculations for total intestinal lactase on lactase activities measured in the proximal jejunum, where they have been shown to be maximal in other mammalian species. On this basis, total intestinal lactase activities that we calculated represent the maximum hydrolyzing capacity of the small intestine. The actual total activity could have been lower. Although the sheep is a ruminant, representing a major difference in intestinal tract function from that in the human, rumen function normally does not begin until after 21 $\mathrm{d}$ of age and is also dependent on institution of grass feeding, so that ruminant function may be delayed with continued milk replacer feeding (42-44). The current study also does not attempt to isolate the effects of chronic hypoxemia from the additional hemodynamic, hematologic, and neurohumoral alterations present secondary to right ventricular outflow tract obstruction and atrial right to left shunting. In this regard, we have previously shown that arterial and central venous pressures are not altered in chronically hypoxemic lambs (6). However, it is possible that an increased level of stress during the initial days of hypoxemia could have partially accounted for our results. Although we have not studied digestive function in lambs with longer periods of chronic hypoxemia, Dalinghaus et al. (Dalinghaus M, personal communication) have shown that growth failure persists in this model for at least 4 wk of hypoxemia. Finally, our model is also potentially limited in that it does not produce in utero hemodynamic alterations or hypoxemia immediately after birth, as would be present in many infants with cyanotic congenital heart disease. We acknowledge this limitation in our model, however, and recognize that there are many cyanotic congenital lesions that are not associated with severe hypoxemia at birth, in which progressive hypoxemia develops only over the first few months of life.

In conclusion, chronic hypoxemia during the newborn period, associated with an intracardiac right to left shunt, produced significant reductions in both the $\mathrm{sp}$ act and total activities of intestinal lactase. This may result in a major decrease in the capacity for digestion of lactose, the predominant dietary carbohydrate of the newborn period. Chronic hypoxemia does not result in significant alteration in dietary intake, which may account for the lack of differences in growth and mucosal cellularity of the small intestine, the portion of the gastrointestinal tract responsible for nutrient absorption. Developing a better understanding of the effects of hypoxemia on the gastrointestinal tract may allow for the development of altered nutritional regimens or enzyme replacement therapies that could ameliorate the effects of chronic hypoxemia on growth.

Acknowledgments. The authors thank Ellen Voss for her technical support and Ann Reisenauer for her technical support and comments on the manuscript.

\section{REFERENCES}

1. Gingell R, Pieroni D, Hornung M 1981 Growth problems associated with congenital heart disease in infancy. In: Lebenthal E (ed) Textbook of Gastroenterology and Nutrition in Infancy. Raven Press, New York, pp 853-860

2. Danilowicz D 1973 Delay in bone age in children with cyanotic congenital heart disease. Radiology 108:655-658

3. Cheek D, Graystone J, Rowe R 1969 Hypoxia and malnutrition in newborn rats: effects on RNA, DNA, and protein in tissues. Am J Physiol 217:642645

4. Menon G, Poskitt E 1985 Why does congenital heart disease cause failure to thrive? Arch Dis Child 60:1134-1139

5. Sondheimer J, Hamilton J 1978 Intestinal function in infants with severe congenital heart disease. J Pediatr 92:572-578

6. Teitel D, Sidi D, Bernstein D, Heymann M, Rudolph A 1985 Chronic hypoxemia in the newborn lamb: cardiovascular, hematopoietic, and growth adaptations. Pediatr Res 19:1004-1010

7. Huse D, Feldt R, Nelson R, Novak L 1975 Infants with congenital heart disease. Food intake, body weight, and energy metabolism. Am J Dis Child 129:65-69

8. Berant M, Alon U, Antebi D, Diamond E, Koerner H, Mordechovitz D 1986 Effects of nonischemic hypoxia on jejunal mucosal structure and function: study of an experimental model in dogs. Pediatr Res 20:1143-1146

9. Lluch M, Ponz F 1962 Influencia de la anoxia sobre la absorción activa de azúcares por el intestino. Rev Esp Fisiol 18:157-162

10. Elliott D, Cheek D 1968 Muscle and liver cell growth in rats with hypoxia and reduced nutrition. In: Cheek D (ed) Human Growth. Lea \& Febiger, Philadelphia, pp 326-336

11. Lifshitz F, Wapnir R, Pergolizzi R, Teichberg S 1976 Intestinal function alterations induced by hypoxia. Gastroenterology 70:908(abstr)

12. Lifshitz F, Pergolizzi R, Lipkin A, Teichberg S, Wapnir R 1976 Alterations in intestinal transport and (Na-K)ATPase in hypoxia. Fed Proc 35:464(abstr)

13. Tejani N, Lifshitz F, Harper R 1979 The response to an oral glucose load during convalescence from hypoxia in newborn infants. J Pediatr 94:792796

14. Bernstein D, Teitel D, Sidi D, Heymann M, Rudolph A 1987 Redistribution of regional blood flow and oxygen delivery in experimental cyanotic congenital heart disease. Pediatr Res 22:389-393

15. Edelstone D, Holzman I 1981 Gastrointestinal tract $\mathrm{O}_{2}$ uptake and regional blood flows during digestion in conscious newborn lambs. Am $\mathrm{J}$ Physiol 241:G289-G293

16. Labarca C, Paigen K 1980 A simple, rapid, and sensitive DNA assay procedure. Anal Biochem 102:344-352

17. Lowry O, Rosebrough N, Farr A, Randall R 1951 Protein measurement with the Folin phenol reagent. J Biol Chem 193:265-275 
18. Tsuboi J 1979 Sugar hydrolases and their arrangement on the rat intestinal microvillous membrane. Membrane Biol 50:101-122

19. Wojnarowska F, Gray G 1975 Intestinal surface peptide hydrolases: identification and characterization of three enzymes from rat brush border. Biochim Biophys Acta 403:147-160

20. Bessey O, Lowry O, Brock M 1946 A method for rapid determination of alkaline phosphatase with 5 cubic millimeters of serum. J Biol Chem 164:321-324

21. Matsukawa R, Terao N, Hayakawa M, Takiguchi H 1983 Effect of prostaglandin $\mathrm{A}_{2}$ on Na-K-ATPase in basolateral plasma membrane of rat intestine in vitro: inhibition of activation of $\mathrm{K}$-dependent $p$-nitrophenylphosphate by NA and ATP. Int $J$ Biochem 15:739-741

22. Glantz S 1987 Primer of Biostatistics. McGraw-Hill, New York, pp 79-82

23. Glantz S, Slinker B 1990 Primer of Applied Regression and Analysis of Variance. McGraw-Hill, New York, pp 302-303

24. Castillo R, Reisenauer A, Kwong L, Tsuboi K, Quan R, Gray G 1990 Intestinal lactase in the neonatal rat: maturational changes in intracellular processing and brush border degradation. J Biol Chem 265:15889-15893

25. Buller H, Montgomery R, Vodek Sasak W, Grand R 1987 Biosynthetic glycosylation and intracellular transport of intestinal lactase-phlorizin hydrolase in rat. J Biol Chem 262:17206-1721

26. Nsi-Emvo E, Launay J, Raul F 1987 Is adult-type hypolactasia in the intestine of mammals related to changes in the intracellular processing of lactase? Cell Mol Biol 33:335-344

27. Quan R, Gray G 1987 Sucrase- $\alpha$-dextrinase reduction by carbohydrate-free diet: conversion of active to inactive enzyme. Gastroenterology 92:1585

28. Bernstein D, Teitel D, Rudolph A 1988 Chronic anemia in the newborn lamb: cardiovascular adaptations and comparison to chronic hypoxemia. Pediatr Res 23:621-627

29. Altmann G 1972 Influence of starvation and refeeding on mucosal size and epithelial renewal in the rat small intestine. Am J Anat 133:391-400

30. Nsi-Emvo E, Raul F 1984 Stimulation of lactase synthesis induced by starvation in the jejunum of adult rat. Enzyme 31:45-49

31. Koldovsky O 1981 Developmental, dietary and hormonal control of intestinal disaccharidases in mammals (including man). In: Koldovsky $\mathrm{O}$ (ed) Carbohydrate Metabolism and Its Disorders. Academic Press, London, pp 482 522

32. Johnson L 1987 Regulation of gastrointestinal growth. In: Johnson L (ed) Physiology of the Gastrointestinal Tract. Raven Press, New York, pp 301334

33. Yamada K, Goda T, Bustamante S, Koldovsky O 1983 Different effect of starvation on activity of sucrase and lactase in rat jejunoileum. Am J Physio 244:G449-G455

34. Granot E, Tamir I, Simcha A, Deckelbaum R 1987 Lactose breath hydrogen analysis in infants with congenital heart disease. Isr J Med Sci 23:1158-1160

35. Strangway A, Fowler R, Cunningham K, Hamilton J 1976 Diet and growth in congenital heart disease. Pediatrics 57:75-86

36. Leonard WR 1989 Nutritional determinants of high-altitude growth in Nunoa Peru. Am J Phys Anthropol 80:341-352

37. Freyre EA, Ortiz MV 1988 The effect of altitude on adolescent growth and development. J Adolesc Health Care 9:144-149

38. Haas JD, Moreno BG, Frongillo EJ, Pabon J, Pareja G, Ybarnegaray J, Hurtado L 1982 Altitude and infant growth in Bolivia: a longitudinal study. Am J Phys Anthropol 59:251-262

39. Stinson S 1982 The effect of high altitude on the growth of children of high socioeconomic status in Bolivia. Am J Phys Anthropol 59:61-71

40. Greksa LP, Spielvogel H, Paredes FL, Paz ZM, Caceres E 1984 The physical growth of urban children at high altitude. Am J Phys Anthropol 65:315-322

41. Phillips L 1986 Nutrition, somatomedins, and the brain. Metabolism 35:7887

42. Walker D 1959 The development of the digestive system of the young animal III. Carbohydrase enzyme development in the young lamb. J Agric Sci 53:374-380

43. Shirazi-Beechey S, Kemp R, Beechey R 1989 Changes in the functions of the intestinal brush border membrane during the development of the ruminant habit in lambs. Comp Biochem Physiol 94B:801-806

44. Walker D 1959 The development of the digestive system of the young animal IV. Proteolytic enzyme development in the young lamb. J Agric Sci 53:381386 